Acta Poetica 31-2

JULIO-DICIEMBRE

$2010(133-164)$

\title{
Blake y el sentido infernal de la Biblia
}

\begin{abstract}
Adrián Muñoz
Es innegable que la tradición religiosa bíblica ha ejercido una honda impronta en la tradición literaria inglesa. Entre los escritores más obsesionados con esta fuente referencial se encuentra William Blake. El presente ensayo ofrece una discusión y una evaluación de la apropiación que Blake hace de la lírica y la retórica bíblica en su obra, particularmente en su The Marriage of Heaven and Hell. En esta obra, la sección "Proverbs of Hell" proporciona un fascinante terreno para sopesar la interpretación veterotestamentaria que realiza Blake. También se examinan los pasajes en que Blake recurre a referentes neotestamentarios para articular su ataque a la religión institucionalizada y defender el papel del Genio Poético.
\end{abstract}

PALABRAS ClAVE: William Blake, literatura y religión, interpretación bíblica.

The biblical tradition has beyond doubt exerted an enormous influence in the English literary tradition. Among the most passionate writers about this referential source William Blake stands out. This paper offers a discussion and an evaluation of the way in which Blake appropriates the lyricism and rhetoric of the Bible in his poetics, especially in The Marriage of Heaven and Hell. In this work, the section "Proverbs of Hell" provides a fascinating area to explore Blake's interpretation of the Old Testament. The essay also examines the passages in which Blake resorts to New Testament motifs in order to shape his attack on organized religion and to uphold the role of the Poetic Genius. 
KeY wORDS: William Blake, literature and religion, biblical interpretation.

Fecha de recepción: 20 de octubre de 2009.

Fecha de aceptación: 23 de abril de 2010. 
Acta Poetica 31-2

JULIO-DICIEMBRE

$2010(133-164)$

\author{
Adrián Muñoz \\ Facultad de Filosofía y Letras \\ Universidad Nacional Autónoma de México
}

\title{
Blake y el sentido infernal de la Biblia ${ }^{1}$
}

\author{
El Mejoramiento forja caminos rectos, \\ pero los caminos torcidos sin \\ mejoramiento son los caminos del Genio. \\ WILLIAM BLAKE
}

En la última "Visión Memorable" de The Marriage of Heaven and Hell (El matrimonio del cielo y el infierno), de William Blake, un Ángel, irritado por la conversación que ha sostenido con un diablo, se consume en llamas de fuego y surge bajo la forma del profeta Elías. La voz poética, que se confunde con la de Blake mismo, dice leer la Biblia en su sentido infernal en compañía de este nuevo amigo (Blake, The Complete Poetry, 43-44). El título de la obra y esta aseveración dejan en claro que la interpretación de Blake en torno de la Biblia no puede ser la convencional. Y sin embargo, Blake no desvalora el pa-

${ }^{1}$ Este ensayo se desprende de una investigación posdoctoral (2008-2010) dentro del programa PROFIP de la Dirección General de Asuntos del Personal Académico. Salvo que se indique lo contrario, todas las traducciones son mías. Todas las citas en inglés de la Biblia provienen de la versión del Rey Jacobo (King James Version); las citas en castellano corresponden a la versión Reina-Valera. 
pel de la fe y el sentimiento religioso; al contrario: Blake es un poeta y un pintor profundamente religioso. De hecho, una parte considerable de su obra es conocida como "Libros proféticos". Así pues, el cristianismo de Blake se nutre de elementos tradicionales, pero también de motivos transgresores y de símbolos ajenos al cristianismo. Aun así, la Biblia poseía para Blake una importancia innegable, toda vez que constituye la fuente de inspiración por antonomasia. El poeta inglés alabó con frecuencia la belleza estilística de la Biblia, una belleza insuperable puesto que aun las mentes más ignorantes podían disfrutarla y comprenderla (Damon, A Blake Dictionary, 46).

La tradición literaria inglesa conoce muchos ejemplos de una fascinación imperante entre varios escritores por la riqueza cultural y simbólica de la Biblia. El ejemplo más claro, sin lugar a dudas, es John Milton (1608-1674), cuyo Paradise Lost se ha convertido en una pieza de culto y quien representó un modelo constante para Blake. Obras como The Pilgrim's Progress de John Bunyan (1628-1688) y The Faerie Queene de Edmund Spenser (1552-1599) fueron para las letras inglesas otros antecedentes importantes que enarbolaron las virtudes de todo cristiano en tierras inglesas. William Blake se destaca entre esta estirpe. En este ensayo propongo revisar las dinámicas de su interacción con el texto bíblico. Dichas dinámicas ofrecen una rica y sui generis reinterpretación de la sapiencia religiosa, al mismo tiempo que articulan una firme postura religiosa más contestataria.

Aunque haré una mención ocasional a la posible influencia de grupos inconformistas en Blake, aquí me interesa explorar particularmente el diálogo que el autor emprende con ciertos pasajes bíblicos. Cabe destacar que una fuente importante para el discurso estilístico de The Marriage ha de hallarse en los escritos de Emanuel Swedenborg; sin embargo, los referentes directos a Swedenborg habrán de circunscribirse en una obra más amplia que se encuentra en preparación. En este sentido, debemos tener en mente que The Marriage constituye ante todo 
una sátira: una sátira de la sabiduría bíblica y de las visiones de Swedenborg, en particular. Desde esta óptica, Blake recurre a las estrategias de Jonathan Swift y Daniel Defoe, pero las enviste de ácidos tomados de su propio taller. En palabras de Northrop Frye:

The Marriage of Heaven and Hell, con la virulenta ridiculización que hace de la sabiduría que habita con la prudencia, con sus risotadas pendencieras hacia las doctrinas de un infierno castigador y un cielo aburrido que los cobardes enseñan a los incautos, es quizás el epílogo de la era dorada de la sátira inglesa (Fearful Symmetry, 201). ${ }^{2}$

Pero aunque sátira, ello no quiere decir que The Marriage carezca de seriedad. La apuesta de Blake por valerse de la retórica bíblica dimana, de hecho, de una profunda reverencia hacia el verbo profético. Al apropiarse satíricamente de la elocuencia bíblica, Blake reforma el mensaje profético.

\section{Los códigos sagrados y la fuente de inspiración}

Antes que nada, debemos estar conscientes de que la política de la apropiación bíblica en Blake está determinada en gran medida por las ideas de Paracelso y Jacob Boehme, los famosos ocultistas y místicos de los siglos XVI y XVII. Paracelso y Boehme - a quienes Blake leyó con sumo interés - creían haber redescubierto antiguas fuentes de sabiduría, las cuales estaban en manos de "sabios paganos"; a través de metodologías alquimistas y cabalísticas, los dos intentaron redirigir su entendimiento del cristianismo. Además, los dos también rechazaban

2 "The Marriage of Heaven and Hell, with its blistering ridicule of the wisdom that dwells with prudence, with its rowdy guffaws at the doctrines of a torturing hell and a boring heaven which are taught by cowards to dupes, is perhaps the epilogue to the golden age of English satire". 
la preeminencia de la lógica y preferían servirse de imágenes visuales y emblemas que manifestaran la presencia divina en este mundo (Ackroyd, Blake, 151), las mismas directrices que guiaron la producción artística de Blake. Es por esta razón que para Blake el papel del profeta-poeta es tan importante: es a través de esta figura, principalmente, como se manifiestan la visión y el verbo divinos. Es en este papel como Blake visualizaba a su sucesor John Milton, y es también de este modo como él mismo se concebía. Al mismo tiempo, la figura del teólogo sueco que se mudaría a Londres, Emanuel Swedenborg, terminaría por completar el caleidoscopio intelectual del joven artista. En varios puntos de The Marriage of Heaven and Hell, las figuras de Milton, Swedenborg y la Biblia se conjugan para articular el discurso blakeano, pero también es posible rastrear otras fuentes de influencia. The Marriage es interesante, entre otras cosas, porque es uno de los textos de la producción blakeana que más íntimamente dialogan con la Biblia.

Aunque considerada como Sagrada Escritura, la Biblia también está sujeta a interpretación y reactualización, así que Blake simpatizó con varios círculos religiosos inconformistas que expresaban sus propias consideraciones a partir de los ideales bíblicos. Uno de estos grupos eran los "Hermanos del Libre Espíritu", quienes declaraban que "el cielo y el infierno no eran sino simples estados del alma en este mundo" (Nuttall, The Alternative Trinity, 219-220). La idea, desde luego, está en completa armonía con la obra de Blake que se estudia en este trabajo: The Marriage of Heaven and Hell. Los Hermanos del Espíritu Libre florecieron en el norte de Europa entre los siglos XIII y XIV, pero durante los siglos XVII y XVIII hubo otros grupos religiosos afines y con ideas igualmente disidentes, como los ranters y los muggletonians, además de crecientes iglesias con tendencias místicas, como la Iglesia Moraviana. Estos grupos compartían el espíritu heterodoxo de los Hermanos del Libre Espíritu en distintas medidas. 
Swedenborg (1688-1772) —quien también habría de producir una honda impresión en autores posteriores como Charles Baudelaire, W. B. Yeats, Carl Jung, Honoré de Balzac, Ralph Waldo Emerson, J. L. Borges, etc.- - redactó bitácoras de sus visiones y sueños místicos, en los cuales contravenía algunos de los fundamentos de la fe cristiana. A ojos de Blake, Swedenborg, al igual que Milton antes de él, eran depositarios de la visión profética que había comenzado con poetas bíblicos como Isaías y Ezequiel. En obras como Divine Love and Divine Wisdom y Heaven and Hell, el teólogo sueco ofrecía las conclusiones que habían derivado tras las conversaciones que, de acuerdo con él, había sostenido con ángeles, tanto en la tierra como en los cielos. Pese a que Swedenborg era un autor místico que profesaba una fe cristiana, varias de sus ideas fueron consideradas heréticas, como la creencia de que el hombre resucitaría en el cielo junto con su cuerpo terrenal. Blake albergaba nociones igualmente controversiales, como el hecho de privilegiar la voz del Diablo. Por esta razón, debemos tener en mente que The Marriage es una composición plena de ingenio y que, además, es "una especie de sátira en contra de la solemnidad swedenborgiana, y exalta al demonio, pero sería absurdo considerar la promoción del demonio como algo meramente cómico, completamente irónico" (Nuttall, The Alternative Trinity, 202). ${ }^{3}$ Lo paradójico es que, en cierto sentido, la exaltación del demonio en Blake dimana de una intensa y radical reinterpretación de la fe cristiana.

Entre 1794 y 1807, Thomas Paine publicó en tres volúmenes su famoso panfleto La era de la razón, un texto de carácter deísta que atacaba abiertamente la teología tradicional y las instituciones religiosas. En 1797, el obispo anglicano Richard Watson publicó como respuesta su Apología de la Biblia, que Blake

3 "Blake's The Marriage of Heaven and Hell is full of wit, is a kind of squib against Swedenborgian solemnity, and it exalts the devil, but here too it would be foolish to take the promotion of the devil as entirely comic, wholly ironic". 
leyó y anotó un año más tarde. Pese a su amor por la palabra profética, en sus notas marginales el autor de The Marriage defiende la postura de Paine y condena la de Watson quien, según Blake, "defiende al Anticristo" (Blake, The Complete Poetry, 612). Tras sopesar ambas perspectivas, Blake con ironía encuentra que Paine "es mejor cristiano que el obispo" (620). Lo interesante es que nuestro autor no favorecía tampoco la filosofía ilustrada por su énfasis en la razón y, en este caso, ello tampoco lo hace abogar por la postura del clérigo. El clérigo, a final de cuentas, representaba para Blake un conjunto de normas represoras. El poeta inglés creía en cuestionar las sanciones y los códigos tradicionales, pero no buscaba cancelar la realidad de Dios ni de su revelación verbal.

The Marriage of Heaven and Hell (1790-1793) es una de las piezas más paradigmáticas de la producción blakeana y posiblemente una de las más célebres junto a las Songs of Innocence and of Experience (1784/1794). Tanto el título como una gran parte del contenido derivan parcialmente del Heaven and Hell de Swedenborg. Así, la política de The Marriage tiene dos directrices primordiales: parodiar los escritos de Swedenborg y criticar algunas prescripciones convencionales. Por un lado, William Blake prometió una "Biblia del infierno" en The Marriage, y, por el otro, construye un intenso diálogo con la retórica bíblica, tanto vetero- como neotestamentaria. Para Blake, el cielo y el infierno no constituyen sitios topográficos de condenación o dicha eterna, sino condiciones existenciales en esta tierra (Tannenbaum, "Blake's News From Hell”, 87); se trata también de valores convencionales que, a ojos del poeta, están tergiversados y se oponen perniciosamente a la vida.

The Marriage puede ser entendido como un preludio a las obras que le siguen, pero en un sentido también es la culminación o desarrollo final de dos obras anteriores: All Religions Are One y There Is No Natural Religion, ambas de 1788. Como The Marriage, las dos fueron escritas en prosa poética y formu- 
lan una suerte de credo y contra-credo; ambas ofrecen un argumento y un listado de principios, motivo que se repite en The Marriage. Allí, la lámina $2^{4}$ ostenta el poema "The Argument", que contextualiza el debate contenido en el resto de la obra; la lámina 4, "The Voice of the Devil", enumera una lista de errores perpetuados por las ortodoxias religiosas:

All Bibles or sacred codes. have been the causes of the following Errors.

1. That Man has two real existing principles Viz: a Body and a Soul.

2. That Energy. calld Evil. is alone from the Body. \& that Reason. calld Good. is alone from the Soul.

3. That God will torment Man in Eternity for following his Energies (Blake, The Complete Poetry, 34). ${ }^{5}$

A continuación, el contra-credo ofrece las visiones contrarias que han de tomarse por lineamientos "infernales":

But the following Contraries to these are True

1. Man has no Body distinct from his Soul for that calld Body is a portion of Soul discernd by the five Senses. The chief inlets of Soul in this age

${ }^{4}$ Casi toda la obra de Blake está compuesta de "libros" que el mismo autor imprimió e ilustró. Es por eso que se habla de láminas, pues Blake literalmente fabricó sus propias obras; en vida, nunca hubo impresiones editoriales de su poesía. Solo algunos de sus diseños llegaron a presentarse en exposiciones. Todas las citas a la obra de Blake en este ensayo derivan de la edición de David Erdman (Blake, The Complete Poetry and Prose of William Blake) y respetan la puntuación y la ortografía originales del poeta.

5 "Todas las biblias, o códigos sagrados, han sido la causa de los siguientes errores:

1. Que el Hombre posee dos principios existentes, a saber: un Cuerpo y un Alma.

2. Que la Energía, llamada el Mal, pertenece solo al cuerpo, y que la razón, llamada el Bien, pertenece solo al alma.

3. Que Dios atormentará eternamente al Hombre por seguir sus Energías." 
2. Energy is the only life and is from the Body and Reason is the bound or outward circumference of Energy.

3. Energy is Eternal Delight. ${ }^{6}$

Desde luego, se trata de lineamientos infernales en un sentido figurado. La idea central es que la energía es correlativa con la imaginación, la creatividad y el deseo, mientras que la razón equivale a la contención y la moral. Las ortodoxias se han encargado de etiquetar arbitrariamente a estas categorías como Mal y Bien. La segunda proposición "verdadera" de este fragmento reformula una afirmación previa de Blake en There Is No Natural Religion: "Mans desires are limited by his perceptions [Los deseos de los hombres están limitados por sus percepciones]" (2). All Religions..., There Is No Natural Religion y The Marriage adoptan una postura muy clara: negar la supremacía de la razón ilustrada (la percepción cientificista) y reivindicar el papel de la imaginación (el Genio Poético) y la vida corporal, pero solo en The Marriage Blake desarrolla a fondo este enfrentamiento.

El rasgo principal de The Marriage of Heaven and Hell es su constante ataque a las verdades preestablecidas del cristianismo y fundamentadas en pasajes de las Sagradas Escrituras. Como sea, William Blake no ataca la fe cristiana en sí misma, puesto que él mismo se asume cristiano, si bien su manera de concebir el cristianismo difiere enormemente de la visión ortodoxa. Más bien, Blake ataca al cristianismo en su aspecto de religión institucionalizada, a la que el poeta concibe como un sistema anquilosado que inhibe la creatividad y la libertad de

6 "Pero los siguientes contrarios son los verdaderos:

1. El hombre no posee ningún cuerpo distinto de su alma, pues el cuerpo no es sino una porción del alma percibida por los cinco sentidos, los principales receptores en esta era.

2. La Energía es la única vida y pertenece al cuerpo, mientras que la Razón es el límite o circunferencia externa de la Energía.

3. La Energía es el deleite eterno." 
los instintos. El autor británico persiste en revalorar y reinstaurar una fe basada en las experiencias visionarias de los profetas y los verdaderos creadores artísticos. El verbo de Dios, como lo entiende Blake, representa un constante flujo de manifestación que cobra forma a través de la palabra de los profetas y los bardos. El verdadero camino que debe transitar el cristiano no es el cumplimiento cabal y automático de los Diez Mandamientos y otros códigos morales, sino el del profeta: un ente donde se manifiesta el Verbo Divino y la facultad creativa que emana de Dios, un vocero que amonesta e instiga a los descarriados.

\section{La dialéctica del proverbio}

El factor detonante del discurso de The Marriage da pie a "El Argumento", la primera sección de la obra. Se trata de pasajes en las Escrituras como el siguiente:

La prudencia velará por ti, la reflexión será tu salvaguarda; te mantendrán aparte de los caminos del mal y de los hombres de palabras engañosas, que abandonan los rectos senderos y se van por caminos oscuros; que ponen su alegría en hacer el mal y se complacen en sus abominaciones, que van por caminos chuecos, por senderos que se pierden (Proverbios 2: 11-15; mi énfasis).

Como veremos, los conceptos en cursivas servirán de guía en la obra de Blake. En "El Argumento", el poeta presenta a un personaje de su mitología personal, Rintrah, que encarna el furor profético o, en otras palabras, que representa la encarnación iracunda del Espíritu de Profecía. Entre llamas de fuego, Rintrah sobrevuela las profundidades. El "vaticinio" refiere que (Blake, The Complete Poetry, 33):

Once meek, and in a perilous path

The just man kept his course along 
The vale of death [...]

Till the villain left the paths of ease,

To walk in perilous paths, and drive

The just man into barren climes ${ }^{7}$

Blake, de manera deliberada, intenta invertir las admoniciones acerca de conservar los senderos de la rectitud y evitar la compañía de los "hombres de palabras engañosas" o villains, quienes conducen hacia los caminos perniciosos que desembocan en la muerte. Resulta significativo que los "caminos del mal" se convierten en "senderos peligrosos" (perilous paths) en Blake, así como los "rectos senderos" devienen en "sendas de calma" (paths of ease). El cambio de adjetivos no es solo un artificio retórico, sino que expresa una convicción ideológica: en lugar de reiterar la idea de que "El justo sirve de guía a su prójimo, pero la conducta de los impíos los hace errar" (Proverbios 12: 26), aquí los “caminos de la rectitud" son calmos y, por tanto, pasivos, mientras que los "caminos del mal", al ser peligrosos, fomentan la actividad, la creatividad.

El espíritu subversivo imperante en la mayoría de los proverbios diabólicos se nutre de la tergiversación de valores que Blake introduce en las primeras cuatro secciones de The $\mathrm{Ma}$ rriage, asentada ya desde "El Argumento"; esta tergiversación alcanza su punto culminante durante la conversión del Ángel en Demonio hacia el final de la obra y donde se anuncia una Biblia del Infierno. La oposición es una constante en esta obra, de allí que el fin deseado sea el de consagrar un matrimonio o alianza entre las partes en pugna. No obstante, dicho matrimonio parece tener una sanción más nominal que real, pues a lo largo de la obra Blake tiende a favorecer sin menoscabo la voz del Diablo por encima de los coros celestiales.

7 “'Otrora manso y en sendero peligroso, / el hombre justo siguió su curso / por el valle de la muerte [...] / Hasta que el hombre vil dejó las sendas de calma / para andar en senderos peligrosos, y conducir / al hombre justo hacia climas estériles". 
Como mencioné más arriba, uno de los puntos principales que nunca debemos perder de vista al leer The Marriage es que Blake rechaza con vehemencia los consejos salomónicos de abrazar la prudencia: "El hombre que se desvía del camino del entendimiento irá a parar en la compañía de los muertos" (Proverbios 21: 16). El poeta inglés considera a la prudencia y el recato como un pernicioso inhibidor de la energía, tipificada como exceso y deseo. Más que una virtud, la prudencia dimana de una impotencia pasional, de una disfunción emocional:

Those who restrain desire do so because theirs is weak enough to be restrained; and the restrainer or reason usurps its place $\&$ governs the unwilling.

And being restrain'd it by degrees becomes passive, till it is only the shadow of desire (Blake, The Complete Poetry, 34). ${ }^{8}$

El juicio de la contención busca aniquilar la energía ajena, pero al mismo tiempo termina por anular la propia. Blake insiste con suculento sarcasmo en que este inhibidor se ampara en justificaciones morales: "Prudence is a rich ugly old maid courted by Incapacity [La Prudencia es una solterona rica y fea cortejada por la Incapacidad]" (35). Así, la moralidad no es sino la careta a la que recurre la debilidad; en este sentido, la mojigatería oculta su propia inseguridad y su flaqueza de espíritu tras la máscara del decoro.

Puesto que la figura de Swedenborg determina parte del aparato satírico de The Marriage, Blake parece haber conferido especial relevancia a la sección de los Proverbios, justamente porque el teólogo no solo nunca mostró interés alguno por la poesía, sino que el Libro de Proverbios bíblico no figuraba en su canon religioso (compuesto de treinta y tres libros)

8 “Aquellos que reprimen el deseo, así lo hacen porque el suyo es lo suficientemente débil para reprimirse; y el represor o razón usurpa su lugar y gobierna sobre los carentes de voluntad. Y al ser reprimido, poco a poco deviene pasivo, hasta que se convierte en una mera sombra del deseo". 
según sus lineamientos (Blake, The Early Illuminated Books, 125; Paley en Bellin y Ruhl, Blake and Swedenborg, 28). De acuerdo con Swedenborg, Proverbios no pertenecía a los libros "inspirados" y, por tanto, no podía ser transmisor del Divino Logos. Blake, de una manera sumamente ingeniosa, combina sus discrepancias con Swedenborg y con la sapiencia convencional religiosa en los Proverbios del Infierno para entablar una suerte de diálogo simultáneo con Swedenborg, la Biblia y autores inconformistas.

Los epigramas de Blake se apoyan en una construcción retórica y alegórica que desde luego hacen clara alusión a los Proverbios en el Antiguo Testamento o Tanaj, adjudicados a Salomón. No obstante, al igual que con las figuras mitológicas de su invención, resulta en extremo difícil desentrañar la significación de varios de ellos. Por lo general, Blake hace uso de elementos de la flora y la fauna para elaborar sus sentencias, las cuales suman en total unos setenta proverbios que no necesariamente siguen un orden temático; pueden estar ora agrupados por tópico, ora no, e incluso es común hallar aislados dos aforismos casi idénticos como "Excess of sorrow laughs. Excess of joy weeps [El exceso de congoja ríe. El exceso de júbilo solloza]", tres líneas abajo: "Joys impregnate. Sorrows bring forth [Los gozos fecundan. Las congojas dan a luz]" (Blake, The Complete Poetry, 36) y aun unos treinta proverbios más adelante: "Prayers plow not! Praises reap not! [¡Las plegarias no aran! ¡Las alabanzas no cosechan!]”, seguido de "Joys laugh not! Sorrows weep not! [Los gozos no ríen. Las congojas no sollozan]" (37). El aforismo es una forma hiperbólica que sirve para expresar favorablemente el significado como acción, no como mero objeto de contemplación, al mismo tiempo que constituye una relación microcósmica con la vida (Birenbaum, Between Blake, 88).

El proceso dialógico con el texto veterotestamentario comienza por retomar casi inocentemente ideas como: "El que 
recoge en el verano es un hijo sensato; pero el que duerme en el tiempo de la siega es un hijo que avergüenza" (Prov. 10: 5), ${ }^{9}$ que Blake enuncia de la siguiente forma: "In seed time learn, in harvest teach, in Winter enjoy [Aprended en tiempos de siembra, enseñad durante la cosecha, disfrutad en el invierno]" (Blake, The Complete Poetry, 35). La idea de que a cada actividad le corresponde una estación está también ampliamente desarrollada en Eclesiastés 3: 1-8, sin duda una de las citas más célebres: "Todo tiene su tiempo, y todo lo que se quiere debajo del cielo tiene su hora. Tiempo de nacer y tiempo de morir, tiempo de plantar y tiempo de arrancar lo plantado...". Blake, de una manera muy sucinta, lo pone así: "Think in the morning, Act in the noon, Eat in the evening, Sleep in the night [Piensa por la mañana. Actúa a mediodía. Come por la tarde. Duerme por la noche]" (37).

Pero también es importante reconocer el deseo consciente de jugar y tergiversar las categorías convencionales de moral y conducta. Cuando Blake recurre a imágenes de la fauna y flora bíblica, ello tiene el propósito de establecer un telón de fondo que permita la subversión: la ira del león, por ejemplo, deja de representar un estado indeseable en un soberano (Prov. 19: 12, 20: 2, 28: 15) para convertirse en un indicador del conocimiento puro y del Genio poético: "The wrath of the lion is the wisdom of God [La ira del león es la sabiduría de Dios]" (Blake, The Complete Poetry, 36). Para poder construir un discurso verdaderamente incendiario, es menester utilizar un conjunto preestablecido de motivos y respuestas culturales y estéticas (Nuttall The Alternative Trinity, 250-251). Por ejemplo, una sentencia como: "As the air to a bird or the sea to a fish, so is contempt to the contemptible [Como el aire al ave o el mar al pez, así es el desprecio al despreciable]" (Blake, The Complete Poetry, 38) sigue de cerca el estilo de Proverbios 26: 11 y 27: 8. De este

\footnotetext{
${ }^{9}$ Piénsese también en Proverbios 6: 6.10.
} 
modo, Blake no solo copia el estilo narrativo y discursivo de la Biblia para imprimirle un tono "profético" a Marriage, sino que juega con símbolos comunes, con los cuales la mayoría de los receptores pueden relacionarse de forma natural. Emplea las figuras salomónicas del Sabio y el Necio, las caracterizaciones ortodoxas del Ángel y el Demonio, sentencias como "Counsel in the heart of man is like deep water; but a man of understanding will draw it out" (Prov. 20: 5) ${ }^{10}$ o bien "Open rebuke is better than secret love" (Prov. 27: 5) ${ }^{11}$ y las trastoca. Sin esta base no podría funcionar el mensaje evangélico de Blake. Proverbios como estos resuenan retóricamente en sentencias "infernales" como: "Sooner murder an infant in its cradle than nurse unacted desires [Antes asesinar a un niño en la cuna que albergar deseos no realizados]" (Blake, The Complete Poetry, 38).

Una de las oposiciones más constantes que encontramos en los Proverbios del Infierno se da entre la figura del sabio y la del necio o insensato, una oposición que también sirve de hilo conductor a través de los Proverbios veterotestamentarios. Salomón dice: "El que anda con los sabios se hará sabio, pero el que frecuenta a los necios se hará daño" (Prov. 13: 20), "La necedad alegra al insensato, el hombre inteligente camina en derechura" (Prov. 15: 21) y "Hasta al necio, si calla, se le tiene por sabio, por inteligente, si cierra los labios" (Prov. 17: 28). Estas ideas son recurrentes. Blake escribe: "A fool sees not the same tree that a wise man sees [Un necio no mira el mismo árbol que mira el sabio]" (The Complete Poetry, 35), que parece respetar la admonición salomónica, pero un poco más adelante escribe: "If the fool would persist in his folly he would become wise [Si el necio persistiera en su necedad, se convertiría en sabio]" (36). Al igual que con las etiquetas de Bien y Mal, de hombre justo y de villano, aquí también comienza Blake a

10 "El consejo en el corazón del hombre es agua profunda, el hombre inteligente sabrá sacarla".

11 "Mejor es reprensión manifiesta que amor oculto". 
trastocar los sentidos. En realidad, el "sabio" no es sino aquel que obedece reglas — actitud pasiva y represora-, mientras que el "necio" actúa sin miramientos - actitud activa y creativa-: "The selfish smiling fool. \& the sullen frowning fool. shall be both thought wise. That they may be a rod [Tanto el necio egoísta y sonriente como el necio huraño y fruncido, pasarán por sabios, para convertirse en varas]" (36). Así, Blake nos apremia a seguir el ejemplo de la insensatez, considerada locura por la normatividad religiosa: "If others had not been foolish, we should be so [Si otros no hubiesen sido necios, nosotros habríamos de serlo]" (37).

La secuencia de los Proverbios del Infierno no sigue una lógica clara ni disposición alguna evidente. Como apunta Harold Bloom (La compañía visionaria, 145), los Proverbios se construyen sobre la dialéctica del Deseo y el Acto, al mismo tiempo que desarrollan una transvaloración de los principios de la ortodoxia religiosa. La dialéctica del proverbio infernal de Blake aboga por una construcción de un nuevo código que trascienda la moralidad de la falsa religión. El carácter heterodoxo de tal empresa exige una actitud feroz y despiadada, una y otra vez se retoman los mismos motivos: "La organización de los Proverbios es compleja, basándose en la asociación suspendida después de que la respuesta preconcebida ha sido alterada por medio de una aparente disociación" (Bloom, La compañía visionaria, 145). Existe, pues, un constante torcimiento de la razón.

El espíritu antinómico casi siempre resulta evidente, pues perdería eficacia si se cobijara en expresiones sutiles. Los proverbios bíblicos advierten: "Una ciudad abierta, sin defensas; así es el hombre que no controla sus impulsos" (Prov. 25: 28), pero Blake embiste: "He who desires but acts not breeds pestilence [Aquel que desea mas no actúa, engendra pestilencia]" (The Complete Poetry, 35); si Salomón instiga al hombre a contentarse con la compañía de su mujer (su "propia cisterna"), a no derramar sus manantiales en las corrientes de agua 
callejeras, el poeta británico declara: "The cistern contains: the fountain overflows [La cisterna contiene; la fuente se desborda]" (36).

La cadena de proverbios no sigue ninguna secuencia definida. Se suceden unos a otros de manera intempestiva, caótica y desbordada, sin duda como una metáfora de los beneficios del exceso de energía. Se siguen unos a otros de la manera más anárquica. Esta "desorganización" sugiere el conflicto inherente entre las categorías de lo Bueno y lo Malo y de quienes suscriben o rechazan dichas etiquetas. El espíritu de estas sentencias es beligerante y sardónico y hay quienes opinan que incluso tienen algo de heracliteano (cfr. Fisher, The Valley of Vision, 8). De acuerdo con Bloom, los proverbios pueden clasificarse en cuatro grupos de acuerdo con afinidades metafóricas:

Uno es enfáticamente apocalíptico y fundamentalmente sexual e incluye imágenes de labranza y cosecha, agua y vino, loa y súplica, bautismo y cópula. Otro se refiere al exceso y la frustración, e incluye proverbios que abordan la fuerza y la debilidad, el deseo y la represión, el cuerpo y el alma, la sabiduría y la estupidez. Un tercer grupo, más claramente antinómico, pone el énfasis en los poderes animales y se organiza alrededor de temas como la violencia, la venganza, la ley y la religión. La cuarta y más amplia categoría está dominada por metáforas de la percepción y encuentra su materia adecuada en los problemas del tiempo y la eternidad, el espacio y la forma, el arte y la naturaleza, los ciclos y las divisiones, y en comparaciones entre los elementos y el cuerpo del hombre (La compañía visionaria, 145-46).

Al mismo tiempo, también es posible suponer que los aparentes contrasentidos en la obra, sobre todo en esta sección de aforismos, podrían servir como una suerte de medida preventiva contra los mecanismos de institucionalización de un "dogma blakeano". 
Acción, profecía y genio

En el prefacio a su poema Milton, Blake escribe: "Would to God that all the Lords people were prophets", citando a la Biblia. ${ }^{12} \mathrm{Al}$ igual que Moisés, nuestro autor desearía que todo ser humano pudiera ser el receptáculo del espíritu profético, mas no para afianzar reglas y prerrogativas litúrgicas y eclesiásticas, sino para rectificar la misión religiosa. Esta misión consiste en cuestionar los dogmas y libertar al individuo.

En El matrimonio del cielo y el infierno, Blake elabora un intrincado sistema de interacción entre fuerzas contrarias. En un nivel, se trata del Bien y el Mal, tipificados por la Razón y la Energía, y que en otro nivel aparecen caracterizados como el Devorador y el Prolífico. El Ángel y el Diablo, desde luego, son otras manifestaciones antagónicas necesarias para construir la dialéctica opositora. La lógica que subyace a la coyuntura de estas parejas supone que lo que erróneamente se considera Bien representa a la Razón, que adopta el papel de Devorador o represor de la energía. Mas como el mismo poeta advierte, la existencia equilibrada de ambos es necesaria para la existencia humana, puesto que la tensión de contrarios supone el verdadero progreso (Blake, The Complete Poetry, 34) o puesto de otro modo, que la oposición constituye la "amistad verdadera" (“Opposition is True Friendship”; Blake, The Complete Poetry, 42). Por esta razón, una gran parte del poema se sustenta en la constante tensión entre el Ángel y el Diablo o Demonio.

El radicalismo y el inconformismo religioso de la Inglaterra de los siglos XVII-XVIII fueron análogos al espíritu de Blake; resulta esclarecedor el hecho de que los grupos radicales recurrían a la retórica de las Sagradas Escrituras al grado de llamar a sus propias enseñanzas The Everlasting Gospel ("el evan-

12 “¡Ojalá que todos fuesen profetas en el pueblo de Jehová, y que Jehová pusiese su Espíritu sobre ellos!” (Números 11: 29). 
gelio eterno"), una locución que Blake mismo utilizaría hacia 1818 para titular un largo poema. La visión inconformista que Blake albergaba rechazaba la autoridad incuestionable de normas, ritos y códigos morales tal y como la habían establecido las distintas iglesias cristianas; antes bien, en Blake el ritual, el dogma y las pretensiones de "santidad" son categorías vacías y carentes de verdadera sustancia sobre las cuales no habría que edificar la fe personal. Poeta imaginativo, Blake opinaba que la realización de la fe cristiana constituía un acto individual, y en ese sentido no debería estar sometida por las exigencias de la colectividad. La fe culmina para Blake con el cuerpo celestial de Jesucristo, una vez que se ha seguido su ejemplo en la Tierra. Los dogmas y las liturgias no son sino formas externas que obnubilan la vista del creyente y por eso Blake busca purgar los ojos imaginativos —o "puertas de la percepción"- con base en una dialéctica "infernal".

A ojos de Blake, Jesús —en tanto el Logos encarnado- representa también la Energía, el Espíritu Profético y el Genio Poético. Uno de los pronunciamientos cruciales que refuerzan este papel agresivo en The Marriage es cuando la voz poética recuerda que Jesús ha venido a traer la espada y no a preservar una falsa e hipócrita paz (Blake, The Complete Poetry, 40; cfr. Mateo: 10: 34 y Lucas 12: 49-53); la idea es que Jesús no tenía el propósito de unir, sino de separar a las "ovejas de los cabríos" (Mateo 25: 31-33). Al igual que Rintrah, el Cristo de Blake es un hombre de acciones, no de preceptos. Jesús es un rebelde, un líder y el ejemplo que el individuo obnubilado debe seguir para "despertar" del sueño de la ignorancia ontológica y ética en que vive; solo así podría aspirar al estado en que se logrará la plena identificación con la divinidad, como refiere el poeta en There Is No Natural Religion (Blake, The Complete Poetry, 3): 
Therefore

God becomes as we are

that we may be as he

$I s^{13}$

La identificación que Blake establece entre el individuo y la divinidad linda en el monismo. La noción bien podría responder a pasajes como el de Lucas 17: 21: "El Reino de los Cielos está dentro de ti", lo que sugiere que el cielo - y por ende el infierno - no son lugares físicos, sino regiones psíquicas y personales. El escritor inconformista Jacob Bauthumley (16131692) reemplazó "cielos" por "Dios" en sus escritos (Nuttall, The Alternative Trinity, 215), lo que refuerza una lectura monista o cuasi-panteísta. La obra y la teología de los ranters, a la cual pertenece Bauthumley, no eran desconocidas para Blake.

Como la mayoría de sus contemporáneos, Blake recibió una formación religiosa cristiana, lo que sin duda alimentó su facultad creativa, pues varias de sus figuras o personajes literarios están estrechamente relacionados con figuras bíblicas. Pero el poeta inglés también siguió por algún tiempo las doctrinas de Emanuel Swedenborg, un teólogo sueco que afirmaba tener conversaciones con los ángeles. En tiempos del poeta inglés, había en Londres una gran proliferación de sectas religiosas, concentradas en su mayor parte en Bloomsbury, no muy lejos de donde vivía el joven Blake. Swedenborg fue un personaje prominente en este contexto y propició la fundación de la Iglesia de la Nueva Jerusalén, con sede en Londres. Los primeros acercamientos de Blake a Swedenborg fueron por medio del padre del poeta, quien era seguidor del pensador sueco, y Blake habría de seguirlo también por algunos años hasta que encontró importantes discrepancias. Siempre una personalidad con tendencias hacia las instancias de genialidad e imaginación

\footnotetext{
13 "Por tanto / Dios deviene a nuestra semejanza / para que nosotros seamos / como Él”.
} 
ilimitadas, el joven grabador y poeta sin duda se habría sentido estimulado por las palabras que Swedenborg escribía:

Como quiera que mediante la Gracia Divina del Señor, las interioridades de mi espíritu me han sido desveladas y en consecuencia me ha sido dado el hablar con espíritus y ángeles, no sólo con los que moran cerca de nuestra tierra, sino con muchos habitantes de otros planetas [...] he sido instruido por ellos acerca de los planetas de que proceden, de la vida, costumbres y forma de adoración divina de sus habitantes [...] [y] se me ha permitido hacer la descripción de las cosas que he visto y oído (De planetas y ángeles, 13).

El visionario sueco afirmaba haber presenciado directamente a los habitantes de las regiones celestiales, quienes le habían llevado por un recorrido a través de distintos cielos e infiernos. En un sentido, nos enfrentamos al mismo tipo de crónicas en $E l$ matrimonio. Swedenborg decía además que: "La relación entre el Cielo y el Infierno es semejante a la que existe entre dos opuestos que actúan uno contra otro y de la acción y reacción de ellos resulta un equilibrio en el que todas las cosas permanecen en orden" (204).

Definitivamente el inquieto Blake tomó prestados de este teólogo elementos que contribuirían a la conformación de su propia concepción teológica, pero ello no impidió la discrepancia y, en consecuencia, instrumentó mordaces ataques contra las doctrinas de Swedenborg. The Marriage of Heaven and Hell es un ejemplo del tipo de influencia que el teólogo y ocultista sueco ejerció sobre el poeta y pintor inglés; el título hace clara referencia a las obras de Swedenborg y el texto mismo menciona su nombre. Emanuel Swedenborg puso por escrito sus visiones, las cuales giraban con frecuencia en torno de un equilibrio entre el bien y el mal, así como también trataban de la naturaleza del reino de los cielos y de sus habitantes. Acerca de este equilibrio, el visionario sueco refería que "las fuerzas 
que actúan manteniendo el equilibrio espiritual son el bien y el mal, pues toda la vida del hombre está en función del bien y el mal, siendo la voluntad el receptáculo en el que actúan tales fuerzas" (214-215; mi énfasis). Swedenborg había atinado al advertir que estas fuerzas intervienen en la voluntad humana, pero había errado al no cuestionar los valores imputados a las categorías del Bien y el Mal. Blake acepta al menos en parte la idea de un equilibrio entre el Cielo y el Infierno, pero al mismo tiempo hace una constante sátira de Swedenborg y de sus doctrinas en The Marriage.

Según Blake, el Genio Poético es también una forma de principio universal, del cual de uno u otro modo derivan todas las religiones del mundo. El Genio Poético, pues, corresponde con la facultad profética. Por ello no es extraño que el poeta inglés sintiera tanta estima por la figura del profeta: The Marriage comienza con Rintrah, figura profética del panteón blakeano, e introduce a Ezequiel, Isaías y Elías en pasajes clave. Aún más: el lenguaje que Blake utiliza emula abiertamente el estilo literario de la Biblia. No solo la forma en que está redactado The Marriage of Heaven and Hell nos trae a la mente versículos bíblicos, sino que incluye sus propios proverbios al estilo del rey Salomón, los que, no obstante, a veces poseen un lenguaje mucho más críptico: "Drive your cart and your plow over the bones of the dead [Conduce tu carro y tu arado sobre los huesos de los muertos]" o "The eagle never lost so much time. as when he submitted to learn from the crow [El águila nunca perdió tanto tiempo como cuando se dedicó a aprender del cuervo]" (Blake, The Complete Poetry, 35, 37).

De una manera preponderante y fundamental, The Marriage supone una labor hermenéutica que Blake ensaya en torno de la Biblia y del cristianismo como religión organizada, pero se trata de una exégesis que recurre a herramientas a veces extravagantes y siempre versátiles (Muñoz, "Hermenéutica y disensión”, 383-425). Desde luego, Blake no se limita a imitar la 
retórica bíblica, sino que incorpora giros lingüísticos propios con el fin de ensayar una gran sátira teológica. La manufactura del discurso satírico en The Marriage es minuciosa y al mismo tiempo despiadada al atacar los valores convencionales:

[The Marriage] ataca el mismo y serio asunto de una cultura que hace de sí misma algo deprimentemente grotesco mediante su abuso de los poderes mentales y corporales. Se trata de un tono urbano, pero con un espíritu feliz y revolucionario. [...] La razón convencional, alias moralidad, lo "angélico", resulta negativamente grotesco porque distorsiona con petulancia la libre energía de la vida. La energía, lo "diabólico", resulta positivamente grotesca porque es peligrosamente creativa y exuberante y porque surge del instinto [...] (Birenbaum, Between Blake, 34). ${ }^{14}$

Sin lugar a dudas, las dimensiones de este tono grotesco encuentran su mayor expresión en los Proverbios del Infierno, la sexta sección de la obra y que abarca las láminas 7 a 10.

El mismo artilugio satírico figura en las Visiones Memorables, en las cuales el sujeto visionario - a través de la voz poética- asiste a una cena en compañía de los profetas Isaías y Ezequiel y donde encontramos las respectivas imposturas de visiones entre el narrador y el ángel ortodoxo; estas visiones se refieren a las concepciones que cada uno de los "personajes" tienen acerca de su destino eterno. En una de estas Visiones Memorables, Isaías y Ezequiel parafrasean las Escrituras al referirse a la "honesta indignación" como la voz de Dios —que emula la lengua como fuego que devora- (Blake, The Complete Poetry, 38; Isaías 30: 27) y al sitio de Judá y la ingesta de estiércol (The Complete Poetry, 39; Ezequiel 4: 4-7).

${ }^{14}$ The Marriage of Heaven and Hell "attacks the very serious theme of a culture that makes itself dismally grotesque through its misuse of mental and bodily powers. The tone is urbane but in a happy revolutionary spirit. [...] Conventional reason, alias morality, the 'angelic', is negatively grotesque because it smugly distorts the free energy of life. Energy, the 'diabolic', is positively grotesque because it is dangerously creative and exuberant, arising from instinct [...]”. 
En otra Visión, además, la voz poética —que para entonces parece ser ya inequívocamente una suerte de diablo - recorre junto con un ángel una serie de supuestos "destinos eternos" (eternal lot) que a cada uno de ellos le corresponde. Al presenciar el tormento que supuestamente le espera en la eternidad a la herética voz poética, de entre las aguas de un mar oscuro e impetuoso en frente de ellos surge una terrible criatura:

\section{[...] and not many stones throw from us appeard and sunk again the scaly fold of a monstrous serpent. at last to the east, dis- tant about three degrees appeard a fiery crest above the waves slowly it reared like a ridge of golden rocks till we discovered two globes of crimson fire. from which the sea fled away in clo- uds of smoke, and now we saw, it was the head of Leviathan. his forehead was divided into streaks of green \& purple like those on a tigers forehead: soon we saw his mouth \& red gills hang just above the raging foam tinging the black deep with beams of blood, advancing toward us with all the fury of a spiritual existence (Blake, The Complete Poetry, 41). ${ }^{15}$}

Vale la pena volver a reparar en la peculiar puntuación de Blake. Esta imprime un ritmo especial, solemne y ceremonioso, un ritmo blakeano que pretende emular el tono de los profetas bíblicos, entre los cuales Isaías y Esdras ejercieron una influencia temprana y perdurable (Damon, A Blake Dictionary, 46). La descripción que Blake ofrece en este pasaje deriva fuertemente de la caracterización de Leviatán como un dragón y una serpiente del mar (Isaías, 27: 1) y del simbolismo desarrollado

${ }^{15}[\ldots]$ y a tan solo un tiro de piedra de nosotros apareció y se sumió de nuevo el escamado lomo de una monstruosa serpiente. Al fin, hacia el este, a unos tres grados de distancia, apareció una fiera cresta por encima de las olas; con lentitud se alzó como un arrecife de doradas rocas, hasta que descubrimos dos globos de fuego carmesí, de los cuales huía el mar en nubes de humo. Y entonces vimos que era la cabeza de Leviatán. Su frente estaba dividida en dos franjas verde y púrpura, como las de un tigre. Pronto vimos su boca y sus aletas rojas pender justo arriba de la fúrica espuma, tiñendo el negro abismo con destellos de sangre, avanzando hacia nosotros con toda la furia de una fuerza espiritual. 
en el libro de Job en torno de Leviatán y de Behemoth, la otra gran bestia veterotestamentaria (Job 40: 15-24 y 41: 7-12). Sin embargo, a medida que la criatura se acerca a los testigos, el Ángel huye hacia un refugio.

En ese momento, el ambiente cambia por completo: ya no se trata de un mar tempestuoso, sino de un apacible banco de arena a orillas de un río, y en lugar de Leviatán, la voz poética se deleita escuchando los armoniosos sonidos de un arpista. Significativamente, Blake sigue aquí la misma evolución narrativa que el Libro del Apocalipsis: tras la descripción y aparición del dragón Leviatán en el capítulo 13, Juan cambia radicalmente de ambiente y en el capítulo 14 presenta una imagen del Cordero de Dios sobre el monte Sión, acompañado de cánticos y loas a Dios:

Y miré, y he aquí el Cordero de pie sobre el monte Sión, y con él estaban los 144.000 que tenían su nombre y el nombre de su Padre escrito en sus frentes. Oí una voz del cielo como estruendo de muchas aguas y como la voz de un gran trueno. Y la voz que escuché era como de arpistas cuando tocan sus arpas (Apocalipsis 14: 1-2).

Como es de esperar, la voz poética en The Marriage acepta con agrado su sino eterno; a continuación, parte en busca del Ángel (Blake, The Complete Poetry, 42). Este cambio radical de "escenografía" poética negocia una invitación a transitar el impío camino de la energía, donde una lectura infernal puede conducir al cielo.

\section{Hacia la Biblia del infierno}

Resulta claro que no podemos desestimar la importancia que tuvo el arraigo del cristianismo y el nacionalismo inglés para 
con la conformación de la cosmovisión blakeana. Sin embargo, es importante advertir que Blake no se limitó solamente a absorber motivos y lenguajes teológicos, sino que estos se vieron motivados por su propia percepción religiosa y estética. Todo esto produjo un complejo sistema teológico y estético que sirve de base a toda la producción blakeana. En The Marriage, el autor se refiere a una Biblia del Infierno:

This Angel, who is now become a Devil, is my particular friend: we often read the Bible in its infernal or diabolical sense which the world shall have if they behave well. I have also: The Bible of Hell: which the world shall have whether they will or no (Blake, The Complete Poetry, 44). ${ }^{16}$

Con su característico tono juguetón y mordaz, Blake afirma que solo si el mundo se comporta bien habrá de recibir el sentido infernal de la Biblia. La Biblia del Infierno, que el mundo recibirá de manera inexorable, presumiblemente trasciende el texto de The Marriage. En otras palabras: The Marriage of Heaven and Hell debe entenderse como la Biblia en su sentido infernal, es decir, la Biblia misma leída a través de ojos "diabólicos". Además, y para equilibrar la Biblia convencional, Blake anuncia una Biblia del Infierno, obra que sucederá a The Marriage. No debemos perder de vista que la lectura infernal de la Biblia es posible una vez que el Ángel y el Demonio han hecho las paces, y más importante es resaltar que esta naciente amistad es posible porque ambos son demonios. Y aún más: antes de que el Ángel se convierta en Diablo, ha adoptado la forma de Elías (Blake, The Complete Poetry, 43), el prototípico profeta del Antiguo Testamento que padece el rechazo y que se hace presente a través de Juan el Bautista y durante la transfi-

${ }^{16}$ Este ángel, ahora convertido en Diablo, es mi amigo particular. A menudo leemos juntos la Biblia en su sentido infernal o diabólico, el cual tendrá el mundo si se comporta bien. Poseo también: la Biblia del Infierno, que el mundo tendrá, lo quiera o no. 
guración de Jesús en el Nuevo Testamento (Mateo 11: 14, 17: 1-3, 10-13; Lucas 9: 7-9; Marcos 6: 14-16).

Para Blake tanto la Biblia hebrea como los Evangelios cristianos representan una fuente sagrada de arte poético y constituyen "derivaciones originales del Genio Poético", como señala en All Religions Are One (Blake, The Complete Poetry, 1), y en este punto ciertamente coincide con la postura de Swedenborg en La verdadera religión cristiana: "Tal es el estilo del Verbo que deviene sagrado en cada enunciado, en cada palabra, a veces en cada letra" (Bellin y Ruhl, Blake and Swedenborg, 10). En gran parte de su obra, el poeta inglés intenta emular "lo sublime" del verso bíblico en contraste con la versificación al estilo clásico. En este sentido, los modelos de Cicerón, Ovidio, Homero y Platón deberían ser "condenados", según afirma en el prefacio a Milton a Poem, por contribuir a la diseminación de guerras y la opresión (Blake, The Complete Poetry, 95; Damon, A Blake Dictionary, 188, 308). Blake pretende, además, que las Hijas de la Memoria (las técnicas clásicas) se conviertan en las Hijas de la Inspiración (la poesía visionaria). Él ve cosas, y las pone en verso e ilumina. En su más largo poema, Jerusalem, escribe además que el estado primordial del ser humano es la sabiduría, el arte y la ciencia (Blake, The Complete Poetry, 146), una ciencia que para él no es sinónimo del empirismo ni del racionalismo. The Marriage of Heaven and Hell es un manifiesto poético que aboga por la libertad energética y se pronuncia en contra de teologías moralizantes que paralizan al espíritu: "Prisons are built with stones of Law, Brothels with bricks of Religion [Las prisiones se erigen con piedras de Ley, los Burdeles con ladrillos de Religión]" (36).

Aunque con fuertes ecos de pasajes bíblicos, no hay que perder de vista que The Marriage es en esencia una composición satírica. Ello también cancela de manera rotunda cualquier aseveración de tendencias satánicas en la obra pese al sitio privilegiado de la Voz del Diablo o los Proverbios del Infierno. 
Blake no rinde culto a Lucifer, ni nada que se le parezca; antes bien: reinterpreta nombres y convenciones desde un punto de vista que las ortodoxias catalogarían de heterodoxo, hereje o, llanamente, "diabólico". Lo mismo vale para la citada Biblia del Infierno.

Lo más seguro es que la "Biblia del Infierno" que Blake promete en la última "Visión Memorable" de The Marriage se refiere a la serie de trabajos visionarios que produjo en los siguientes años antes de partir de Londres a Felpham en West Sussex. Normalmente se conoce a estos trabajos como "las profecías de Lambeth" y estaban destinadas a re-producir las narrativas bíblicas de la Torá, particularmente del Génesis y el Éxodo. Así, la Biblia del Infierno comprendería America a Prophecy (1793), Europe a Prophecy (1794), The Song of Los (1795), The Book of Los (1795), The Book of Urizen (1794) y The Book of Ahania (1795). The Book of Urizen y The Book of Los serían los intentos de Blake por recontar el Libro de Génesis; The Book of Ahania reformularía el Éxodo y, por último, America y Europe emularían los libros de los profetas. En todo caso, el proyecto de la Biblia del Infierno nunca fue concretado como lo había visualizado el autor y los títulos mencionados poseen autonomía, si bien comparten un mundo mitopoético.

Dada la importancia que los Salmos atribuidos al Rey David han ejercido en la lírica europea, resulta llamativo que estos no causaran mayor influencia en la poética de Blake. Como he resaltado en este ensayo, fueron sobre todo la retórica proverbial salomónica y la narrativa profética las que determinaron en mayor medida el estilo de este autor. En el caso de The Marriage, la escritura visionaria de Swedenborg resultó igualmente influyente. La retórica de The Marriage, en concreto, se apoya en una argumentación binaria y contestataria que continúa la tradición de tratados religiosos que se escribieron antes de Blake y de Swedenborg acerca del cielo y del infierno, muchos de los cuales emanaron de círculos protestantes. La ideología 
protestante rechaza la idea del purgatorio como una última oportunidad para expiar culpas y "ganarse" el cielo, de modo que solo las obras realizadas en vida garantizan el acceso al cielo; el mayor mérito, pues, consiste en cumplir los preceptos religiosos a través de la Iglesia. Blake no comulgó bien a bien con estas creencias; mucho menos con la teoría calvinista de la predestinación. Si bien no se pronunció en favor de la existencia de un plano intermedio entre el cielo y el infierno, sí sostuvo que era posible alcanzar la gracia infinita o la espiritualidad mediante facultades humanas.

El sentido infernal de la Biblia, aunque diabólico, evita caer en la solemnidad dogmática, casi al grado de rayar en lo insensato. Ciertamente, en más de una ocasión la retórica aforística de Blake se acerca al contrasentido: "Excess of sorrow laughs. Excess of joy weeps [El exceso de congoja ríe. El exceso de júbilo solloza]". La argumentación blakeana en The Marriage, y que alcanza su máxima expresión en los Proverbios del Infierno, es sumamente profunda a causa de la dimensión que proyectan a expensas del maniqueísmo intelectual y moral que supone el convencionalismo religioso. La oposición lógica de los proverbios diabólicos no hace sino poner de relieve el contrasentido que, en realidad, tienen las categorías de Bien y Mal como las entendemos habitualmente. Al respecto, Bloom (Blake, The Complete Poetry, 898) apunta que si bien la retórica de los proverbios es antinómica, su argumento no lo es, sino que depende de la definición de un Acto (no cualquier acto, sino el ser, el hecho mismo de actuar y llevar a cabo un deseo). Y para comprender los oráculos cabalmente se requiere de mucha disposición, de tener las herramientas necesarias, de imaginación y del deseo de realizarse: "He whose face gives no light, shall never become a star [Aquel cuya faz no irradia luz, jamás se convertirá en estrella]" (Blake, The Complete Poetry, 35).

The Marriage of Heaven and Hell satiriza la religión institucionalizada y las prédicas de Swedenborg; dicha sátira está 
mediada por estrategias que Blake obtiene de John Milton, su mentor poético: "Es como si Blake tomara la imagen usada por Milton de la inspiración satírica como una aseveración prescriptiva y con plena consciencia buscara el medio más satírico posible" (Tannenbaum, "Blake's News From Hell", 94). ${ }^{17}$ Leer la Biblia en su sentido infernal supone violentar los entendimientos convencionales de fe, moralidad y santidad, pero también supone ensanchar nuestro horizonte para incluir los puntos de vista erradicados del sentimiento religioso por los artífices del dogma. De este modo, The Marriage es una sátira profética o visionaria que enarbola el papel de la acción (o exceso) y condena la inacción (la razón). La Voz del Diablo nos invita alegóricamente a leer la Biblia en su sentido infernal, un sentido que defiende la Energía Prolífica y celebra el grito del profeta en el desierto.

\section{REFERENCIAS}

AcKroyd, Peter, Blake [1995], London, Vintage Books, 1999.

LA BIBLIA. Antigua versión de Casiodoro de Reina (1569) y revisada por Cipriano de Valera (1602) <http://iglesia-de-cristo.org/ biblia/> [fecha de consulta: marzo de 2010].

LA BIBLIA. King James Version (1611) <http://etext.virginia.edu/kjv. browse.html>.

Bellin, Harvey F. y Darrell Ruhl (eds). Blake and Swedenborg. Opposition is True Friendship, New York, Swedenborg Foundation, 1985.

Birenbaum, Harvey, Between Blake and Nietzsche. The Reality of Culture. London-Toronto, Associated University Presses, 1992. Blake, William, The Complete Poetry and Prose of William Blake, David Erdman (ed.), commentary Harold Bloom, New YorkLondon-Toronto-Sydney, Anchor Books-Doubleday, 1988.

17 "It is as if Blake took Milton's image of satiric inspiration as a prescriptive statement and deliberately sought the best possible satiric mode $[\ldots]$ ". 
BlaKe, William. The Early Illuminated Books, edited with Introduction and notes by Morries Eaves, Robert N. Essick, Joseph Viscomi, New Jersey, The William Blake Trust-Princeton University Press, 1993 (The Illuminated Books 3).

Bloom, Harold, La compañía visionaria: William Blake, trad. Mariano Antolín Ratto y Pablo Gianera, Buenos Aires, Adriana Hidalgo, 1999.

Damon, Foster, A Blake Dictionary. The Ideas and Symbols of William Blake [1965], with a New Foreword by Morries Eaves, University of New England Press, 1988.

Fisher, Peter F., The Valley of Vision. Blake as Prophet and Revolutionary [1961], Northrop Frye (ed.), Hanover-London, University of Toronto Press, 1971.

FrYe, Northrop, Fearful Symmetry. A Study of William Blake [1947], Princeton University Press, 1990.

MuÑoz, Adrián. "Hermenéutica y disensión con el canon: La doctrina de la energía en la Tripurātāpin̄ Upanisad y The Marriage of Heaven and Hell”, Estudios de Asia y África 136, XLIII, 2, 2008: 383-425.

NutTall, A. D., The Alternative Trinity. Gnostic Heresy in Marlowe, Milton, and Blake [1998], Oxford-New York, Oxford University Press, 2007.

Swedenborg, Emanuel, De planetas y ángeles. (Antología) [1977], Jesús de Imirizaldu (ed.), Madrid, Miraguano, 1988.

Tannenbaum, Leslie, "Blake's News From Hell: The Marriage of Heaven and Hell and the Lucianic Tradition", English Literary History, vol. 43:1, 1976, 74-99. 